Education Offices, Woodlands Road, Middlesbrough, Cleveland TS1 3BN

To the Editor:

2nd June, 1982

Dear Sir,

\title{
SAFETY IN EXERCISE
}

As the Safety Officer for the British Association of Advisers and Lecturers in Physical Education it is always a pleasure to read any serious works dealing with safe practices in Physical Education.

In the March 1982 issue of the British Journal of Sports Medicine I was drawn to the articles dealing with (1) "Riskfactors in Trampolining, illustrated by six injuries" and (2) "Neck Injury with Quadriplegia: an avoidable training hazard".

Sadly, I thought that the conclusions in both cases were not the best. It would have been much better to have looked at the circumstances which produced the injury rather than outlawing, in the case of (1) Trampolining as an activity in schools and (2) The use of an activity which has been regularly enjoyed for decades by teachers and pupils in our schools.

I thought that the photographs used in the trampoline article were alarming. I hope that they were not taken in a British school because they showed totally unacceptable practices. ${ }^{*}$ I should like to urge that those who supervise children on trampolines should themselves have undergone acceptable training in the practice and teaching of trampolining and should be especially conscious of safe practices to avoid foreseeable injuries.

May I also distinguish between a trampoline - the big bedded rebound apparatus; and the trampette - the small, angled, rebound bed. The latter is more difficult to handle than the former, in my opinion. It's use in British schools is already limited and very rightly so.

As for the back-rocking movement outlined on p. 59, there would have been no problem if the coach/teacher had checked the safety points before the start viz. position of feet, match of partners' weight, previous experience, state of readiness and personal fitness of performers, the establishing of a real understanding of what the movement achieved for the performer, an awareness of limits of movement range, etc. Lastly and perhaps significant, what are the needs of a 37 year old man in such training regimes? Positive guidance is better than anxious conjecture.

$$
\text { Yours faithfully, }
$$$$
\text { D. H. Williams (P.E. Adviser) }
$$

*No, they were taken by the author in a Danish school. - Ed. 